Corrigendum: Persisting positron emission tomography lesion activity and Mycobacterium tuberculosis mRNA after tuberculosis cure

Stephanus T Malherbe, Shubhada Shenai, Katharina Ronacher, Andre G Loxton, Gregory Dolganov, Magdalena Kriel, Tran Van, Ray Y Chen, James Warwick, Laura E Via, Taeksun Song, Myungsun Lee, Gary Schoolnik, Gerard Tromp, David Alland, Clifton E Barry III, Jill Winter, Gerhard Walzl, the Catalysis TB-Biomarker Consortium

Nat. Med. 22, 1094-1100 (2016); published online 05 September 2016; corrected after print 19 October 2016

In the version of this article initially published, one of the authors of the Catalysis TB-Biomarker Consortium was incorrectly identified as Nelita Burger. The author's name is Nelita Du Plessis. The error has been corrected in the HTML and PDF versions of the article.

\title{
Erratum: Reply to "Neutrophils are not required for resolution of acute gouty arthritis in mice"
}

Christiane Reinwald, Christine Schauer, Janka Zsófia Csepregi, Deborah Kienhöfer, Daniela Weidner, Marie Malissen, Attila Mocsai, Georg Schett, Martin Herrmann \& Markus Hoffmann

Nat. Med. 22, 1384-1386 (2016); published online 06 December 2016; corrected after print 19 January 2017

In the version of this article initially published, the units $(\mathrm{ml})$ for values reported in the methods are incorrect. The correct unit should be $\mu \mathrm{l}$. The error has been corrected in the HTML and PDF versions of the article.

\section{Erratum: PIM1 kinase regulates cell death, tumor growth and chemotherapy response in triple-negative breast cancer}

Fara Brasó-Maristany, Simone Filosto, Steven Catchpole, Rebecca Marlow, Jelmar Quist, Erika Francesch-Domenech, Darren A Plumb, Leila Zakka, Patrycja Gazinska, Gianmaria Liccardi, Pascal Meier, Albert Gris-Oliver, Maggie Chon U Cheang, Anna Perdrix-Rosell, Manar Shafat, Elodie Noël, Nirmesh Patel, Kristen McEachern, Maurizio Scaltriti, Pau Castel, Farzana Noor, Richard Buus, Sumi Mathew, Johnathan Watkins, Violeta Serra, Pierfrancesco Marra, Anita Grigoriadis \& Andrew N Tutt

Nat. Med. 22, 1303-1313 (2016); published online 24 October 2016; corrected after print 26 January 2017

In the version of this article initially published, the western blot in Figure 2a for the BT474 cell line was incorrect. In addition, one of the accession codes for gene expression data for the Guy's Hospital TNBC-enriched cohort was incorrect. The errors have been corrected in the HTML and PDF versions of the article. 